\title{
Valparaíso-Chile: towards a senior-citizen-friendly town?
}

\author{
G. Fadda ${ }^{1}$, A. Cortés ${ }^{2} \&$ A. Olivi ${ }^{3}$ \\ ${ }^{1}$ Facultad de Arquitectura, Universidad de Valparaíso, Chile \\ ${ }^{2}$ Carrera de Arquitectura, Universidad Federico Santa María, Chile \\ ${ }^{3}$ Facultad de Arquitectura, Universidad de Valparaíso, Chile
}

\begin{abstract}
The development of global cities with a cultural potential - as in the case of Valparaíso, recently declared Patrimony of Humankind - offers some exceptional opportunities in Quality of Life for their inhabitants, as long as those cities are set up as friendly and inclusive. However, the dynamics of a Global City accelerate some processes of social differentiation and exclusion in which senior-citizens - the subjects of our study - are an especially vulnerable group. On the other hand, these dynamics show new trends of population migration between cities that, according to their calling, attract or repel different age groups.

This paper falls within the context of a Research Project (FONDECYT \# 1061179) titled "Calidad de Vida del Adulto Mayor en el Hábitat Urbano: Estudio del Caso de Valparaíso" (Quality of Life of the Senior Citizen in a Urban Habitat: Valparaiso, a Case Study). This paper starts by integrating the concepts of Quality of Life, Sustainable City, Aging, and Neighborhood, in order to establish the possible relationships between aging and quality of life in the urban context of Valparaíso. This implies to investigate how certain conditions in the urban habitat impact the quality of life of the eldest group of the population.

Keywords: quality of life, sustainable city, aging, neighborhood, Valparaiso, demography, migrations, social nets, friendly neighborhoods, perception of senior-citizens.
\end{abstract}




\section{Introduction}

Thus outlined, the subject under study seems broad and complex. In order to validly address it a triangulation approach was used, i.e., an analysis combining several quantitative and qualitative methodological instruments. Such methods include the GIS system for georeferentiation of demographic data from the Census 2002 to maps of Valparaíso; the Focus Groups directed to the players themselves; the Delphi Survey to collect the opinions of experts in the field; the Senior-citizen Survey, interviews, etc.

Herein we intend to discuss some initial results obtained in our field research through the Focus Group method with the support of some GIS maps. The Focus Group is a social investigation procedure that collects information through group interaction. It's a communicational experience promoting the construction of collective meaning from the subjective views of participants (Morgan [1] and Sharken [2]) that contribute their own perceptions and insights, a pertinent and relevant expertise in conceptual and terminological terms. This was one of the qualitative instruments applied in the research in order to meet the objective of studying the perceptions and expectations of quality of life from senior-citizens in Valparaíso.

This Paper starts by clarifying its basic underlying concepts. Then it discusses the case of Valparaíso, the results on perceptions had by senior-citizens concerning their quality of life, and some preliminary conclusions from the study.

\section{Initial clarifications}

Before going into our subject, it's necessary to define four key concepts for the development of this paper. They are: Quality of Life, Sustainable City, Aging, and Neighborhood.

\subsection{Quality of life}

For Glatzer y Zapf, the quality of life is "a multidimensional term of well-being meaning that 'objective' life conditions are satisfactory and that there is a high degree of 'subjective' well-being; in addition to the individual satisfaction of necessities, this includes the collective well-being" (cited by Palomba [3]). Thus, quality of life is a multidimensional concept containing both material and nonmaterial, objective and subjective, individual and collective aspects of well-being and wealth. "All of these aspects are closely related to each other. Objective life conditions affect the ability that people have to exercise control over their own environment; on the other hand, the subjective life experiences relate to the evaluation and feelings of people towards their life conditions" (Palomba [3]).

Due to its complexity, the concept of Quality of Life may be interpreted in a number of ways, depending on whether the evaluation factors are considered in reference to the life of a person or of a community (Brock [4]). Also, it should be outlined as a social construction or construct, forged by a collective observer and 
in which, in addition to the objective measures and quantitative indicators, other measures and indicators of a subjective and qualitative nature must be taken into account. Thus we will be able to evaluate the quality of people's lives only if, in addition to objective data, the observers' expertise and subjective experiences are also included (Fadda and Jiron [5]).

\subsection{Sustainable city}

The "Brown Agenda" (Bartone et al [6]) covers an array of urban problems that are directly related to the lack of sustainability in the development of our cities. Among them are especially relevant for this case: segregation; deficits in equipment, services, and infrastructure; poor quality in construction and design of houses and their equipment; occupation of spaces unfit for human life; deficiencies in soil condition; inappropriate planning of urban traffic; poor management of solid and liquid wastes; water and air pollution; and flooding or landslide risks. Additionally, the precariousness of environmental quality in poor urban neighborhoods has been recognized as one of the most urgent and largest scale problems having an impact on the health and well-being of its inhabitants (BID-UN [7]).

These problems, in addition to being directly related to the unsustainability in the development of our cities, mainly impact the urban population's more vulnerable segments, such as the poor, the women, the senior-citizens, and especially those who fit into more than one of the above categories. Current planning intends to revert such problems, and among its high-priority objectives is that of increasing the quality of life of such segments and therefore urban sustainability.

\subsection{Aging}

Faced with a global trend of population aging, the Madrid International Plan of Action (United Nations [8]) outlined the challenge to build societies that would integrate their senior-citizens. That is to say, a society that would be functional to the participation of the elderly; the recognition of their potential for economic, social, and cultural contribution; the extension of their activity and social inclusion; the ties of intergenerational solidarity at family and community levels; the eradication of poverty; and the consolidation of a healthy culture of aging, emphasizing the prevention of health issues and risks that are characteristic of this life stage. As one of its high-priority guidelines, the Madrid Plan proposed the implementation of a favorable environment for aging. To this end, the Plan encourages the development of senior-citizen-friendly neighborhoods and cities. This implies that a study of the situation of senior-citizens in big cities should be given first priority in order to be able to implement any improvements in this regard, both in urban design and the fitting-out of public spaces and the restructuring of urban space (CEPAL [9]).

In this sense, Valparaíso is an especially interesting case, since it's the city with the higher aging rate among the 3 major Chilean cities. According to the Census 2002, nationwide senior-citizens amount up to $11.4 \%$, while they amount 
up to $13.94 \%$ in the municipality of Valparaíso. Also, Valparaíso has some characteristics that may prove either advantageous or disadvantageous for an urban integration of senior-citizens. Among other features, this is a coastal town with a patrimonial and cultural character, a peculiar topography, and emerging real estate dynamics.

\subsection{Neighborhood}

With the purpose of creating an instrument for analysis, the notion of "neighborhood" was studied. According to this notion, a neighborhood is characterized by having its "own personality", being a "family of families", and representing a "micro-town." It's also an intermediate step between the city and the individual, and is a perfectly well-known, familiar space that the inhabitants' personal and social perceptions feel as their own. Neighborhoods are also characterized by being functional and mainly residential. Their respective areas are also limited by distances that may be covered by a pedestrian, allowing each one of them to be a sociological reality based on the notions of proximity and vicinity.

\section{Case study: Valparaíso}

\subsection{Neighborhood demarcation}

The geography of Valparaíso, in spite of being formed by a diversity of unique areas with their own characteristics, is characterized by the consistence of its urban development. The urban layout lies around a Northern-oriented bay on a narrow coastal plain, surrounded by 42 hills forming an amphitheater overlooking the wide scenery of the Pacific Ocean. Its topography has been a key element in the town's existence and its development process. It has conferred very unique characteristics to the public spaces: a large number of the streets, alleys, avenues, stairs, and terraces are wide balconies or belvederes upon the bay and ocean.

Based on the theoretical characterization assumed, a delimitation of neighborhoods was proposed for the town of Valparaíso. Neighborhoods were delimited according to a double division into sectors. The first division had six longitudinal areas, while a second division was defined by the major gorges between the hills that traversely intersect the longitudinal areas. Thus, 97 neighborhoods were demarcated: 3 of them downtown and 94 in the hills.

The three downtown neighborhoods are spatially interconnected in sequence, something that doesn't happen at the hills, where gorges are usually a barrier between one neighborhood and the next. This same feature does not only confer a peculiar structure to the neighborhoods and the city, but also acts as a form of relationship between the inhabitants and their town: within a hill, neighborhood contacts are usually very strong and frequent. Relationships occur there at a primary level (neighborhoods, basic community equipment). On the contrary, by reason of topography contacts among the different hills are scarce. An exception 
to the above is Camino Cintura, the main road communicating the hills that follows the winding at the 100 spot height level (100m above sea level.) Social relationships among neighborhoods take place especially between each of them and the downtown, when metropolitan equipment and services are accessed. In this case the flow is mainly transverse, occurring through the roads that join the hills and the downtown.

\subsection{Demography and migration}

The Valparaíso Metropolitan Area (VMA), also known as Greater Valparaíso, is a conurbation formed by 5 municipalities: Valparaíso, Viña del Mar, Concón, Quilpué, and Villa Alemana. While the subject under study in this paper is the city of Valparaíso, it's crucial to understand its relationship with the adjoining municipalities, since they have had an incidence in the demographic and migratory processes experienced by the city and that have consequently caused its aging.

The increase in the number of senior-citizens in the town of Valparaíso has been a demographic process mainly associated with changes in population birth rates and internal migrations within the VMA. The latter were the result of a prolonged economic stagnation suffered by the city during the $20^{\text {th }}$ century.

This situation of widespread stagnation throughout the $20^{\text {th }}$ century is the most significant in the condition of the town of Valparaíso. This contrasts very sharply with the considerable expansion that took place at the surroundings, as manifested in the fast growth experienced by the towns of Viña del Mar, Quilpué, and Villa Alemana, which at present are continuous urban sprawl that make up the Greater Valparaíso. This has translated into a significant increase in the population of these municipalities, especially in Quilpué and Villa Alemana, that became commuter towns for Viña del Mar, Valparaíso, and even Santiago (the capital city). In turn, an improvement in the road system has helped to the connections between these municipalities and the more consolidated urban areas in the VMA.

Data from the last two census periods (1982-1992, 1992-2002) shows that the municipality of Valparaíso, which was already characterized by a minimum growth $(0.26 \%)$ in the $1982-1992$ period, was during the next decade the only municipality in the region with a negative growth rate $(-0.24 \%)$, (CELADECEPAL [10]).

Its economic growth has also been smaller than that of the aforementioned towns, which have shown a strong growth since the 40's due to import substitution policies that attracted manufacturers, as well as external trade development policies from the mid-1970s that have encouraged agro industrial exports (Consultoría-BID [11]).

Valparaíso's unfavorable economic situation, also associated with the restrictions on growth and expansion within its consolidated urban areas, has prompted a significant migration of the working age (15-64 years old) population to municipalities that offer better work opportunities and real estate offers.

Thus, from the most recent migrants -those who have migrated during the last five years - only $20 \%$ moved to Santiago, while $40 \%$ moved inward in the 
region, especially to Viña del Mar (11\%), Quilpué (7\%), and Villa Alemana $(6 \%)$, feeding the fast growth of these municipalities (Consultoria-BID [11]).

Viña del Mar received a massive immigration of families from high-revenue sectors as a consequence of the 1906 earthquake. The city began to absorb a small but sustained migratory flow of the most well-off inhabitants of Valparaíso, who built major mansions, buildings, public spaces, and recreational areas. In those years started an increased growth of this town, which has remained ever since much higher than that of Valparaíso. In fact, toward the mid-1980s - i.e., 100 years after Viña del Mar became a municipality (1878) its population became larger than that of Valparaíso (Consultoria-BID [11]).

Currently this migratory flow is also associated to the greater real estate offer in these municipalities, which is partly due to their residential role within the VMA. In this regard, Quilpué and Villa Alemana have concentrated low density single-family homes, while Viña del Mar has been densified with a high-rise building offer for mid-high and high socioeconomic groups. On the other hand, the municipality of Valparaíso caters to a market of apartment buildings for a middle socioeconomic level, in addition to recycled homes. Another residential trend in this municipality has been the consolidation of the Curauma area in Placilla which in the past years and in spite of their outlying location has taken on a significant role (Consultoria-BID [11]).

On the other hand, Valparaíso poses serious obstacles to growth and urban expansion, partly due to an increase in the price of slope construction, difficulties in access to high areas in the hills, and the risks implicit in living near gorges and steep slopes. This has been a significant disincentive for settlement in the municipality, especially for young people which are in the process of building a new home and who are forced to look for more economic residence options in other municipalities in the Greater Valparaíso (CELADE-CEPAL [10]). Consequently the relative weight of older population has increased in the town of Valparaíso.

\section{Results: the quality of urban life as perceived by senior- citizens}

All of what has been stated above led us to research the impact that the urban habitat of Valparaíso has on the older group of its population. To this end we tried to capture, through the Focus Group application, the perceptions that senior-citizens had on their environment.

Based on maps created using GIS, four groups were selected applying criteria of senior-citizen density per areas of Valparaíso; socio-economic differences; ecological zones; and location in a number of neighborhoods throughout the city. Thus two Focus Groups were carried out downtown, and two in the hills. The two thematic axes outlined were the senior-citizens' relationship to their physical environment (home, neighborhood, city), and to their significant environment (formal and informal networks).

The results obtained can be classified into three types of senior-citizen perceptions with regard to: 1) aging; 2) urban habitat of Valparaíso; and 3) their 
social networks. Given the objective of this paper, herein we will cover the last two of them.

\subsection{Perception of Valparaíso's urban habitat}

An analysis of the accounts on the perception of the urban habitat allows us to recognize that people stand before the city from a double perspective: as inhabitants and as visitors. This unfolding of perspectives begets different views and appraisals. The visitor's perspective gives them the ability to look at the city from the outside and project themselves into the picture of a patrimonial Valparaíso as something new and different. In many cases, when referring to the patrimony they position themselves more in the collective mindset than in their life experiences, and the inhabitancy of what is patrimonial takes on a positive connotation. The inhabitant's perspective instead is that of the senior-citizen facing the access, traffic, and mobilization problems that characterize the urban space. The inhabitancy of the city is viewed from their daily routines, by visualizing the challenges inherent to Valparaíso's morphology. Thus, as visitors, the beauty of the stairways, narrow streets and hills is perceived; while as inhabitants, this positive and picturesque aspect of the city takes on a negative connotation.

Urban decay, especially the poor quality of the streets, is the aspect identified as more challenging by the participants, as it puts in risk their physical integrity when walking around town. People living in the hills routinely go downtown to carry out formalities at public offices, use urban services, or simply to save in domestic purchases.

"We're aging and the town is becoming more and more deteriorated, the roads, you just have to walk and you stumble... you just stumble" (Textual quote [12]).

Despite the difficulties experienced when moving between the hills and downtown, in general people confer a positive value to the inhabitancy of the hills. This positive perception could result from a set of attributes making the hills a more friendly, healthy space, where a communal dimension helps the creation of bonds and support networks. Living in the hills is construed as inductive of social identity; people are recognized and reaffirmed through their neighborhoods.

"For example I arrived in this hill when I was 22... There's a house that's broken, damaged by earthquakes and everything, but if I'd have to leave it I'd die, just imagine, it's been more than 60 years in there. Living in the same neighborhood, in the same hill, I adore that, doesn't matter that houses are not as pretty anymore, because you get used to it" (Textual quote [12]).

The communal dimension, the fact that people know each other in person or are related as family to others, is a factor that makes senior-citizens feel safer when living in the hills.

According to the accounts, living in the hills allows them to enjoy a better quality of life since it turns out to be healthier, both socially and physically. Less polluted air, lower traffic of vehicles, and the views are very valued elements. To 
go downtown by walking is perceived as an exercise that helps to stay in good physical shape. Hills take on a positive dimension as opposed to downtown, which is seen as a space where there is no community life.

"What's positive about living in the hills are the views, there's not as much noise or smog as in downtown, because in downtown you can hardly communicate because of so many vehicles as there are there... especially if you're a bit hard of hearing" (Textual quote [12]).

Despite living in the hills, the accounts from senior-citizens are traversed by a sensation of insecurity that they experience both in public and domestic spaces. They recognize themselves as a vulnerable group from this perspective, and an easy target for urban micro-criminality.

\subsection{The perception of social networks}

Loneliness prompts people to create mechanisms to compensate a lack of significant ties. Faced with this loss, they generate social networks in order to establish relationships of mutual support, solidarity, and company. Thus a reciprocal exchange mechanism is set up, allowing them to face life more securely.

Those who experience aging in a situation of complete loneliness are essentially backed up by these formal and informal networks as only sources of psycho-social support. Among informal networks, the accounts evidence that neighbors and friends make up the most direct support circle in daily life, while family is perceived as more distant and absent.

Formal networks identified by senior-citizens are divided in two groups: peer networks, and public services.

One of the formal networks that operates most significantly on behalf of senior-citizens are clubs. Most of the surveyed subjects participate in groups formed either privately as pensioners' clubs from the companies where they used to work, or under the auspices of the Church. The perception that they have of clubs is entirely positive, and they are validated as a meeting space that has brought a positive change in the life of Valparaíso's senior-citizens. Typically they are relatively new groups. It also should be noted that, in addition to the ability to socialize and endure the moments of solitude, in some cases these groups offer to senior-citizens an opportunity to carry out some productive activities that would allow them to feel active and generate a small revenue.

The social support received by them from such networks is mutually supplemented and contributes to globally meet their needs. The kind of support they receive ranges from the creation of socialization and participation spaces to the fulfillment of basic needs such as those related to health care.

Among the public services offered by the governmental establishment, participants are regularly in touch with clinics or health care facilities, and occasionally in touch with municipal entities intended to offer some type of support to senior-citizens.

In general, the subjects voiced a very positive perception on both informal and formal networks, appreciating the importance of having a reliable support that helps them to improve their quality of life. 


\section{Preliminary conclusions}

In summary, with regard to the city of Valparaíso senior-citizens perceive that:

- There are many urban deficiencies that are dangerous for their physical security;

- It's an unsafe place, causing a sensation of insecurity, fragility, and lack of protection;

- While being physically difficult for them, the hills have plenty of other positive meanings, such as:

- Hosting neighborhoods that are filled with community ties and create bonds of friendship and solidarity among neighbors,

- Hosting a network of human relationships that are an essential support for the life of senior-citizens, and

- Being a space healthier and more fulfilling than downtown.

- As a patrimonial site, it's full of positive attributes and picturesque aspects in its urban structure. However, this is not a relevant aspect for their quality of life; and

- Social networks are wide and heterogeneous, provide emotional support and allow them to stay active.

Finally, it can be concluded that the irregular topography of Valparaíso, that could be considered as something negative for the quality of life of seniorcitizens, turns out to be an advantage for achieving a friendlier and more sustainable city. This is attributed to the wealth of the community life and the habitat provided by the hills, which meet most of the requirements initially mentioned for being considered "neighborhoods." On the other hand, downtown doesn't provide the same wealth of community life, so the qualities detected in the hills should be stimulated and urban conditions particularly impacting seniorcitizens should be improved.

\section{References}

[1] Morgan, D. Focus Group Interviewing. Handbook of Interview research. Context and method. G. Holstein. Sage Publications, California, pp. 141159, 2001.

[2] Sharken Simon, J. How to conduct a Focus Group, The Grandsmanship Center Magazine, 1999. Online. www.tgci.com/publications/99fall/ conductfocusgp.html.

[3] Palomba, R. Recomendaciones para Realizar Investigaciones Sobre Redes de Apoyo y Calidad de Vida: Agenda de Investigación y Métodos e Instrumentos para Estudios Cualitativos y Cuantitativos. Notas de Población, pp. 251-261, 2003.

[4] Brock, D. Medidas de Calidad de Vida en el cuidado de la salud y la ética médica. La Calidad de Vida. M. y. S. Nussbaum, A (compiladores). Fondo de Cultura Económica, México, pp. 135-181, 1996. 
[5] Fadda, G. \& Jiron, P. "Quality of Life: a Methodology for Urban Research". Environment and Urbanization Vol. $11 \mathrm{~N}^{\circ}$ 2, pp. 261-270, 1999.

[6] Bartone, C. R., Bernstein, J. \& Leitmann, J. "Managing the environmental challenge of mega-regions". International Conference on Managing the Mega-Urban Regions of Asian Countries: Policy Challenges and Responses. Bangkok: Asian Institute of Technology, 1992.

[7] BID-NU. Nuestra Propia Agenda. Comisión de Desarrollo y Medio Ambiente de América Latina y el Caribe, 1990.

[8] NACIONES UNIDAS. Declaración Política y Plan de Acción Internacional de Madrid sobre el Envejecimiento. II Asamblea Mundial sobre el Envejecimiento, Naciones Unidas, Madrid, pp.31, 2003.

[9] CEPAL. La situación de las personas mayores, Conferencia Regional Intergubernamental sobre envejecimiento: Hacia una estrategia regional de implementación para América Latina y el Caribe del Plan de Acción Internacional de Madrid sobre el envejecimiento, Santiago de Chile, 19 al 21 de Noviembre de 2003, Documento de Referencia DDR/1, CEPAL, Naciones Unidas, Santiago de Chile, 2003. Online http://www.eclac.cl/celade/noticias/paginas/1/13611/FINAL-DSC-1Espanol.pdf.

[10] CELADE-CEPAL. Informe Final Estudio "Desarrollo Humano y Social: Diagnóstico, Análisis y Proyecciones, Región de Valparaíso”. Plan Regional de Desarrollo Urbano y Territorial. Santiago, Chile, pp. 247, 2005.

[11] CONSULTORÍA-BID. Preparación Programa de Recuperación y Desarrollo Urbanos de Valparaíso. Segundo Informe de Avance. Diagnóstico, BID, pp. 332, 2005.

[12] Textual quote. Opinions from participants in Focus Groups. 